Corresponding Author: $\mathrm{Ai}$

Mardhiyah; email:

aimardiyah@gmail.com

Published: 7 February 2022

Publishing services provided by

Knowledge E

(c) Ai Mardhiyah. This article is distributed under the terms of the Creative Commons

Attribution License, which permits unrestricted use and redistribution provided that the original author and source are credited.

Selection and Peer-review under the responsibility of the IVCN Conference Committee.

\section{Hope Among Adolescents With Thalassemia in Indonesia: A Cross-Sectional Study}

\author{
Ai Mardhiyah'1,2*, Henny Suzana Mediani², Santhna Letcmi Panduragan ${ }^{1}$ \\ and lyus Yosep ${ }^{2}$ \\ ${ }^{1}$ Faculty of Nursing, Lincoln University College, Malaysia \\ ${ }^{2}$ Department of Pediatric Nursing, Faculty of Nursing, Universitas Padjadjaran, Indonesia \\ ORCID \\ Ai Mardhiyah: https://orcid.org/0000-0002-3185-6771
}

\begin{abstract}
Adolescents with thalassemia suffer from complex problems, which can include psychosocial issues, self-image and self-confidence problems, and disruption in school or social activities. Hope is a fundamental multidimensional psychological concept that refers to a person's belief that desired outcomes will be achieved on the basis of rational and potential goals. This study aimed to examine hope and its associated factors among adolescents with thalassemia in Indonesia. A cross-sectional study was carried out at the Thalassemia Polyclinic in four general public hospitals in West Java, Indonesia. The following inclusion criteria were used: (1) adolescents (10-19 years) who obtained frequent blood transfusions; (2) able to write, read and participate; and (3) aware of their own diagnosis. A convenience sample strategy was used to choose the participants. The Children's Hope Scale was used to measure the outcome. Linear regression analyses were used to investigate the factors associated with hope. The mean overall hope score among adolescents with thalassemia was 3.34 (SD = 1.15). The mean of agency was $2.78(S D=1.37$ ) and of pathway was $3.89(S D=2.01)$. Age, transfusion period and hemoglobin explained $26.1 \%$ of the variance in the overall hope score; $23.8 \%$ was explained by the agency domain, and $30.1 \%$ by the pathway domain. This study demonstrated that hope plays a unique role in adolescents with thalassemia. As a result, it is critical to develop information and empirically based interventions that help adolescents' caregivers to enhance their feelings of hope.
\end{abstract}

Keywords: adolescents, hope, thalassemia, Indonesia

\section{Introduction}

Thalassemia is a natural disease and long-term treatment than can negatively affect the patient's physical appearance and psychological problems [1]. Thalassemia affected adolescent's physical performance such as cooley facias, mongoloid eyes, depressed nasal bones, maxillary hypertrophy, enlarged liver, and spleen, reduced muscle mass, growth failure, and delayed puberty [1,2]. Psychological problems have a stronger impact, especially on adolescents, because adolescence is a period of transition from children to adulthood, there are psychosocial changes to meet the needs of self-identity and greater autonomy $[3,4]$. 
Adolescents with thalassemia suffer from complex problems, including psychosocial problems, self-image and self-confidence problems, and disruption in school or social activities $[5,6]$. The prevalence of psychological problems in adolescent's thalassemia major was high, including $60.9 \%$ experienced of severe anxiety, $59.4 \%$ stress, and $18.8 \%$ depression [7]. In addition, previous studies reported that thalassemia adolescents suffered from hopelessness, moderate loneliness, higher anxiety, and low self-esteem compared to healthy adolescents [8-10]. Psychological problems can become a barrier to adherence to diet and recommended medication, and have negative effects on selfcare and treatment outcomes including quality of life [11].

Hoe is a fundamental multidimensional psychological concept that refers to a person's belief that desired outcomes will be achieved on the basis of rational, potential goals [12]. Hope is a motivating factor for undertaking or continuing acts to achieve a goal and can be promoted or maintained by individual support networks and interpersonal relationships [13]. In addition, studies suggest that optimism is considered an inner source [14], that is vital to seeking the sense of one's life, unity, optimistic self-assessment, and self-assessment [15], which can eventually contribute to self-actualization [16]. According to [12], hope and expectations reflect individual perceptions regarding their capacity to clearly conceptualize goals, develop specific strategies to achieve these goals (pathways thinking), initiate and maintain motivation to use these strategies (agency thinking). According to [17] hopes are human strengths which are characterized by one's ability to set clear goals, develop specific strategies to achieve goals (pathways) and maintain motivation to use existing strategies. Previous evidence has been reported that hope was associated with a health indicator such as coping, self-esteem, and quality of life [18-20].

In chronic diseases such as thalassemia, hope has a significant meaning. Several studies suggested that people with less hope were more likely to suffer from depression and maladaptive coping than people with high hopes [21-23]. Thalassemic adolescent reported to have maladaptive coping, which shows feelings of helplessness and hopelessness $[11,24]$ In contrast, thalassemia patients who have high hopes take action to avoid complications by adhering to iron chelation treatment, maintaining the frequency of control to the doctor and getting regular blood transfusions [21,23]. However, the focus of systematic research on the meaning of hope has not been carried out across cultures. To uncover the meaning of hope in chronic diseases, [22] has conducted studies of patients who have chronic diseases using open questionnaires.

Research about exploring hope conducted by [25] concluded that there are several factors that can influence expectations, namely social support, religious trust, and 
control. Hope has a close relationship with social support. In the research on patients whom suffering from chronic diseases [26] concluded that family and friends were generally identified as a source of hope for sufferers of chronic illness in several activities such as visiting a place, listening, speaking, and providing physical assistance. Meanwhile, [27] identifies the defense of family role relationships as crucial for the level of expectation and coping. Research by [21] in Pakistan showed that male children had more physical and emotional health problems than female children. However, they were high hope than female children; there was a negative relationship between physical and emotional health problems and hope of children. Therefore, this study aimed to hope and its associated factors among adolescents with thalassemia in Indonesia.

\section{Methods}

\subsection{Study design and Setting}

A cross-sectional study was carried out at the Thalassemia Polyclinic in four general public hospitals in West Java Indonesia. Data was collected from April to May 2021.

\subsection{Sample}

The following criteria were applied to patients, who were: (1) adolescent (10-19 years), who got frequent blood transfusions, (2) they were able to write, read and participate and (3) completely aware of their own diagnosis. Patients having a history of mental illness or cognitive impairment were eliminated, as were those who were illiterate and unable to complete a survey. A convenience sample strategy was used to choose the participants who were eligible for the study. Eighty percent of the 150 adolescents with thalassemia who matched the inclusion criteria and had an effective response rate.

\subsection{Ethical consideration}

The study has been authorized in compliance with ethical standards by an affiliated university's ethical committee. Patients were given informed consent forms and surveys to sign. Everyone who participated was assured of secrecy and the opportunity to decline or withdraw completely independently and without penalty at any moment. 


\subsection{Measures}

The demographic datasheet includes information such as age, gender, educational level, race, family income, and co-morbidity information. The Children's Hope Scale (CHS) is a questionnaire developed by Synder [28]. The Hope Scale for Children is a downward extension of the Hope Scale for Adults and is used to examine children's hope. The Children's Hope Scale is comprised of six statements that are rated on a Likert-type scale from 1 (never) to 6 (always). The agency and the pathway played a significant role in determining the scale's components. The Cronbach Alpha coefficient in the current study was 0.705 .

\subsection{Procedure}

Adolescents completed self-report surveys after providing written, informed consent. In the study period from April to May 2021, the adolescents included 150 patients who visited a hospital for outpatient care as well as 120 participants who participated in an online questionnaire. It was only after the researcher had fully discussed the aims of the investigation and gained managerial consent that he published information about the study. Adolescents who have a chronic condition and agreed to participate in the survey completed it. If any participants had questions as they went through the survey, the researcher was there to help them immediately.

\subsection{Data analysis}

This study was employed by the ANOVA/t test to describe the average quotas for different demographic and clinical categories. Linear regression analyses were used to investigate the factors associated with hope. The statistical analyses were performed using SPSS for Windows (22.0), with 0.05 being considered statistically significant.

\section{Results}

The demographic and clinical characteristics of the patients are summarized in Table 1. Of the 120 people, sixty-five (54.17\%) were boys, whereas 55 (45.83\%) were girls. Patients ranged in age from ten to nineteen years, and 35.83 percent of participants were primary students. In terms of clinical characteristics, 64.17 percent received blood transfusions once every one to three months, 4.17 percent had comorbidity, and 77.5 
TABLE 1: Demographic and clinical characteristics and the score of hope among adolescents with thalassemia $(n=120)$

\begin{tabular}{|c|c|c|c|c|c|}
\hline & \multirow[b]{2}{*}{ n (\%) } & \multicolumn{4}{|c|}{ Hope } \\
\hline & & Mean & SD & $\mathrm{F} / \mathrm{t}$ & $p$-value \\
\hline \multicolumn{6}{|l|}{ Age } \\
\hline 10-15 & 76 (63.33) & 3.54 & 1.77 & 2.31 & 0.036 \\
\hline $16-19$ & $44(36.67)$ & 4.17 & 1.55 & & \\
\hline \multicolumn{6}{|l|}{ Gender } \\
\hline Boy & 65 (54.17) & 3.07 & 1.17 & 1.55 & 0.516 \\
\hline Girl & $55(45.83)$ & 4.19 & 1.82 & & \\
\hline \multicolumn{6}{|l|}{ Education level } \\
\hline Elementary school & $38(35.83)$ & 2.51 & 1.05 & 1.31 & 0.197 \\
\hline Junior high school & 25 (20.83) & 3.32 & 1.13 & & \\
\hline Senior high school & $32(26.67)$ & 3.64 & 1.43 & & \\
\hline \multicolumn{6}{|l|}{ Transfusion period } \\
\hline Once in $1-3$ months & 77 (64.17) & 2.44 & 1.07 & 0.47 & 0.011 \\
\hline Once in 3-6 months & $43(35.83)$ & 3.29 & 1.43 & & \\
\hline \multicolumn{6}{|l|}{ Comorbidity } \\
\hline Yes & $5(4.17)$ & 2.76 & 1.01 & 1.82 & 0.242 \\
\hline No & 115 (95.8) & 2.93 & 1.99 & & \\
\hline \multicolumn{6}{|l|}{ Hemoglobin (mg/dl) } \\
\hline $5-6$ & 27 (22.5) & 3.08 & 1.77 & 3.18 & 0.021 \\
\hline 7-8 & $93(77.5)$ & 4.71 & 1.55 & & \\
\hline
\end{tabular}

TABLE 2: A descriptive statistic of hope in studied participants $(n=120)$

\begin{tabular}{l|l|l} 
& Mean \pm SD \\
\hline $\begin{array}{l}\text { Overall } \\
\text { score }\end{array}$ & hope & $3.34 \pm 1.15$ \\
\hline Agency & $2.78 \pm 1.37$ \\
Pathway & $3.89 \pm 2.01$
\end{tabular}

percent had hemoglobin levels of 7 to $8 \mathrm{mg} / \mathrm{dl}$. Among the variables in this study, the difference in the hope scores was significant across groups, including age $(t=3.621, p$ $=0.025)$, transfusion period $(t=4.167, p=0.011)$, and hemoglobin $(t=3.008, p=0.021)$.

Table 2 presents descriptive statistic of hope in studied participants. The mean overall hope score among adolescents with thalassemia was $3.34(\mathrm{SD}=1.15)$. The mean of agency was 2.78 (SD=1.37) and pathway was 3.89 (SD=2.01).

Table 3 shows that all of the independent variables associated with thalassemic adolescents' hope in univariate analysis $(p<0.025)$ were inserted into model. Age, transfusion period, and hemoglobin associated contributed significantly to the variance 
TABLE 3: Hierarchical multiple regression analysis results of hope in adolescent with thalassemia $(n=120)$

\begin{tabular}{l|l|l|l} 
Variable & $\begin{array}{l}\text { Overall hope score Agency B (SE) } \\
\text { B (SE) }\end{array}$ & pathway B (SE) \\
\hline Age & $0.158(0.074)^{*}$ & $0.173(0.074)^{*}$ & $0.153(0.095)^{*}$ \\
\hline Transfusion period & $-0.187(2.081)^{*}$ & $-0.158(2.615)^{*}$ & $-0.192(2.274)$ \\
\hline Hemoglobin & $0.193(0.078)^{*}$ & $0.071(0.018)$ & $0.135(0.071)$ \\
$\mathrm{R}^{2}$ & 0.261 & 0.238 & 0.301 \\
Note: ${ }^{*} \mathrm{p}<0.05 ;{ }^{* *} \mathrm{p}<0.001$. & &
\end{tabular}

in hope. Age, transfusion period, and hemoglobin, explained $26.1 \%$ of the variance in overall hope score, $23.8 \%$ for agency domain, and $30.1 \%$ for pathway domain.

\section{Discussion}

Hopefulness has been shown to aid the growth of health in teenagers and young adults with an illness [29]. In addition, a larger degree of hope is connected with more hope and people who are hopeful are trying to conduct themselves in healthy behaviours, even with their severe symptoms, which help chronic diseased healing [22]. People with hope may tolerate more suffering because they are better equipped for it. Additionally, [30] states that hopeful individuals have a variety of life goals, including preserving good health, throughout a variety of life sectors. A "goal impediment" diagnosis like thalassemia (or, alternatively, other chronic diseases) might help people who have an interest in and some support for treatment do more research, work on collaboration with others in their treatment group, and pursue options that are available outside of what they believe is best treatment, all in order to free themselves from what their diagnosis would mean for them [30].

Hopefulness has been shown to aid the growth of health in teenagers and young adults with an illness [29]. In addition, a larger degree of hope is connected with more hope and people who are hopeful are trying to conduct themselves in healthy behaviours, even with their severe symptoms, which help chronic diseased healing [22]. People with hope may tolerate more suffering because they are better equipped for it. Additionally, [30] states that hopeful individuals have a variety of life goals, including preserving good health, throughout a variety of life sectors. A "goal impediment" diagnosis like thalassemia (or, alternatively, other chronic diseases) might help people who have an interest in and some support for treatment do more research, work on collaboration with others in their treatment group, and pursue options that are available 
outside of what they believe is best treatment, all in order to free themselves from what their diagnosis would mean for them [30].

This study found that age, blood transfusion period, and hemoglobin were associated with hope. According to [19] antecedent variables that are relevant for distinguishing one's hopes are first, beliefs about the potential to overcome problems, secondly selfesteem, and thirdly social support. But the results of other studies mention some essential factors that influence hope in adolescent, it consists of social support, faith and religion, and control factors. A study by [31] in Greece examined 74 adolescent thalassemia. The results of the study show that thalassemia adolescents have high expectations. About $66 \%$ teenage thalassemia reported that they would be able to take care of themselves, $95 \%$ of our teenage thalassemia was not particularly bothered about their routine blood transfusion, $90 \%$ had no complications and $82 \%$ responded that they had good or very good information on their own health condition. There is also a significant relationship between expectations and therapeutic knowledge. Their excellent knowledge of therapy has enabled them to project their passion for the family and everyday life in the future.

However, there are several limits that must be considered. The study's variables could not be clearly distinguished in regards to which one is the cause and which one is the effect. Secondly, this research did not examine age-specific advances in disease and progression together with clinical characteristics such as iron chelation. These factors will have a major impact on how patients respond to this issue. This strategy would allow for a more comprehensive examination of the effects of developmental stage on adolescents' hope. It is recommended that future research investigate the moderator/mediator effect of a patient's stage of development on the correlation of hope. Last but not least, given the focus on the self-reputation of adolescences, care is needed due to unconscious prone to one-methods and to the need, together with a group of key respondents (for example, parents, teachers and/or clinics, to further research based on a multi-method analysis approach). Finally, because the sample was drawn from the West Java region, we were able to rule out the potential that results were influenced by the quality of organizational assistance offered or other contextual variables, which must be carefully evaluated.

\section{Conclusion}

The current study demonstrates that hope plays a unique role in adolescents with thalassemia. As a result, it's critical to develop information and empirically proven 
interventions that help adolescents' caregivers make the most of them enhance their hope. The current research emphasized the critical nature of applying evidence-based practices that strengthen cognitive-motivational qualities, such as hope, with the goal of aiding teenagers in better coping with their disease and any accompanying unfavorable experiences.

\section{Conflict of interest}

None.

\section{Funding}

This research did not receive any specific grant from funding agencies in the public, commercial, or not-for-profit sectors

\section{References}

[1] Cappellini MD, Porter JB, Viprakasit V, Taher AT. A paradigm shift on betathalassaemia treatment: How will we manage this old disease with new therapies? Blood Reviews. 2018;32(4):300-11.

[2] Taher AT, Weatherall DJ, Cappellini MD. Thalassaemia. Lancet. 2018;391(10116):15567.

[3] Mohamadian F, Bagheri M, Hashemi MS, Komeili Sani H. The effects of cognitive behavioral therapy on depression and anxiety among patients with thalassemia: A randomized controlled trial. Journal of Caring Sciences. 2018;7(4):219-24.

[4] Hassan SME, Azzab SESHI El. Study of the health instructions effect on quality of life and psychological problems among children with thalassemia. International Journal of Studies in Nursing. 2016;1(1):16.

[5] Behdani F, Badiee Z, Hebrani P, Moharreri F, Badiee AH, Hajivosugh N, et al. Psychological aspects in children and adolescents with major thalassemia: A casecontrol study. Iran J Pediatr. 2015;25(3):e322-e322.

[6] Thirafi KN. Psychological well-being pada penderita talasemia. Jurnal Psikologi. 2017;9(2).

[7] Khamoushi F, Ahmadi S, Karami-Matin B, Ahmadi-Jouybari T, Mirzaei-Alavijeh M, Mahboubi $\mathrm{M}$, et al. Prevalence and socio-demographic characteristics related to 
stress, anxiety, and depression among patients with major Thalassemia in the Kermanshah County. J Biol Today's World. 2015;4(3):79-84.

[8] Chong LT, Chong MC, Tang LY, Ramoo V, Chui PL, Hmwe NTT. The relationship between psychological distress and religious practices and coping in Malaysian parents of children with thalassemia. Journal Pediatric Nurse. 2019;48:e15-20.

[9] John K, Haliasos N. Depression and thalassemia in children, adolescents and adults. Heal Sci J. 2013;7:239-46.

[10] Tajvidi M, Zeighaini MS. The level of loneliness, hopelessness and self-esteem in major thalassemia adolescents. Sciences Journal Iran Blood Transfus Organ. 2012;9(1):36-43.

[11] Bagul A, Porwal A, Jain M. Psychosocial problems in thalassemic adolescents and young adults. Chronicles Young Sciences. 2013;4:21.

[12] Corn BW, Feldman DB, Wexler I. The science of hope. Lancet Oncol. 2020;21(9):e452-9. https://doi.org/10.1016/S1470-2045(20)30210-2

[13] Geller G. The tyranny of hope. Hastings Cent Rep. 2019;49(4):3. https://doi.org/10.1002/hast.1026

[14] Bright FAS, Kayes NM, McCann CM, McPherson KM. Understanding hope after stroke: A systematic review of the literature using concept analysis. Top Stroke Rehabil. 2011;18(5):490-508.

[15] Haugan G. Self-transcendence, well-being, and nurse-patient interaction in cognitively intact nursing home patients. 2013.

[16] Kelly P, Hayman R, Shekerdemian LS, Reed P, Hope A, Gunn J, et al. Subdural hemorrhage and hypoxia in infants with congenital heart disease. Pediatrics. 2014;134(3):e773-81.

[17] Shane J. Lopez and C.R. Snyder. The Oxford handbook of positive psychology. $2^{\text {nd }}$ ed. Oxford Handbooks Online; 2012. Available from: https://www.oxfordhandbooks. com/view/10.1093/oxfordhb/9780195187243.001.0001/oxfordhb-9780195187243

[18] Bahryni S, Bermas H, Tashvighi M. The self-efficacy forecasting based on hope to life and resiliency in adolescents suffering from cancer. Biomed Pharmacol Journal. 2016;9(3):1147-56.

[19] Ciarrochi J, Parker P, Kashdan T, Heaven P, Barkus E. Hope and emotional wellbeing: A six-year study to distinguish antecedents, correlates, and consequences. The Journal of Positive Psychology. 2015;10:1-13.

[20] Y®lmaz Karadag F, Saltoglu N, Ak Ö, Ç冈nar Ayd囚n G, Senbayrak S, Erol S, et al. Foot self-care in diabetes mellitus: Evaluation of patient awareness. Primary Care Diabetes. 2019;13(6):515-20. 
[21] Muazzam A, Javed S. Predictors of caregiver's burden: Interplay of physical and emotional health and perceived hope in children with thalassemia and hemophilia. Pakistan Journal of Social and Clinical Psychology. 2013.

[22] Schiavon CC, Marchetti E, Gurgel LG, Busnello FM, Reppold CT. Optimism and hope in chronic disease: A systematic review. Frontiers in Psychology. 2016;7:2022.

[23] Perveen S. Hope and health related life quality among thalassemic patients. 2019;10(2):73-6.

[24] Koutelekos J, Haliasos N. Depression and thalassemia in children, adolescent and adults. Health Sciences Journal. 2013;7(3):239-46.

[25] Pollock MJ, Wennerstrom A, True G, Everett A, Sugarman O, Haywood C, et al. Preparedness and community resilience in disaster-prone areas: Cross-sectoral collaborations in South Louisiana, 2018. American Journal of Public Health. 2019;109:S309-15.

[26] Ebrahimi H, Hasankhani H, Namdar H, Khodadadi E, Fooladi M. Dealing with chronic illness: Experiences of Iranian families of persons with multiple sclerosis-A qualitative study. Multiple Sclerosis International. 2017;2017.

[27] Hildenbrand AK, Barakat LP, Alderfer MA, Marsac ML. Coping and coping assistance among children with sickle cell disease and their parents. Journal of Pediatric Hematology/Oncology. 2015;37(1):25.

[28] Snyder CR, Cheavens J, Sympson SC. Hope: An individual motive for social commerce. Group Dynamics: Theory, Research, and Practice. 1997;1(2):107.

[29] Haase JE, Heiney SP, Ruccione KS, Stutzer C. Research triangulation to derive meaning-based quality-of-life theory: Adolescent resilience model and instrument development. International Journal of Cancer. 1999;12:125-31.

[30] Snyder CR. The past and possible futures of hope. Journal of Social and Clinical Psychology. 2000;19(1):11-28.

[31] Koutelekos J, Haliasos N. Depression and thalassemia in children, adolescents and adults. Health Science Journal. 2013;7(3):239-46. 